\title{
Fast and High-throughput Evaluation of Photodynamic Effect by Monitoring Specific Protein Oxidation with MALDI-TOF Mass Spectrometry
}

\author{
Shiwei Zhou, Guangxue Feng, Shaowei Wang, Guobin Qi, Min Wu, and Bin Liu* \\ Department of Chemical and Biomolecular Engineering, National University of Singapore, Engineering Drive 4, Singapore \\ 117585, Singapore.
}

\section{TABLE OF CONTENTS:}

$\star$ EXPERIMENTAL SECTION

$\star$ Figure SI-1 The structure of TPETH.

$\star$ Figure SI-2 MS Fingerprint of E. coli by MALDI-TOF MS

$\star$ Figure SI-3 MALDI-TOF MS detection of $E$. coli in different periods of photodynamic treatment.

$\star$ Figure SI-4. The accuracy and repeatability of oxidation rate and bactericidal rate.

$\star$ Figure SI-5. MALDI-TOF MS of pure proteins after photodynamic treatment for different illumination time

$\star$ Figure SI-6 Photodynamic treatment for E. coli with different photosensitizers.

$\star$ Figure SI-7 Fingerprints of different bacteria species detected with MALDI-TOF MS.

$\star$ Table SI-1 The oxidized mass peaks in different bacteria species after photodynamic treatment.

$\star$ Figure SI-8 Fingerprint of $H L-60$ cells detected with MALDI-TOF MS.

$\star$ Figure SI-9 MS fingerprint of the mixture of E. coli and MRSA. 


\section{EXPERIMENTAL SECTION}

Materials and instruments. Ultrapure water (18.2 M $\Omega$ ) was supplied by Milli-Q Plus System (Millipore Corporation, United States). Phosphate buffer saline $(10 \times \mathrm{PBS}, 100 \mathrm{mM})$ buffer with $\mathrm{pH}=7.4$ is a commercial product of $1_{\mathrm{st}}$ BASE from Axil Scientific Pte Ltd in Singapore, which is used to prepare the $1 \times$ PBS buffer solution. Methylene blue (MB), rose bengal (RB), protoporphyrin IX (PpIX), 2,5-dihydroxybenzoic acid (DHB), sinapinic acid (SA), trifluoroacetic acid (TFA), streptomycin, and penicillin were purchased from Sigma Aldrich. Chlorin e6 (Ce6) was obtained from Santa Cruz Biotechnology. The Roswell Park Memorial Institute (RPMI) 1640 medium was purchased from Invitrogen. Fetal bovine serum (FBS) was purchased from Life Technologies. Tetraphenylethenethiophene (TPETH) was synthesized as the reference, with its structure in Figure SI-1 in supporting information (SI). Actonitrile (ACN) was obtained from VWR Chemicals. Hydrogen peroxide $\left(\mathrm{H}_{2} \mathrm{O}_{2}, 30 \%\right)$ was supplied by Tokyo Chemical Industry (TCI) Co., Ltd. The Cell Counting Kit-8 (CCK-8) was purchased from KeyGEN BioTECH Co., Ltd. (Nanjing, China). All the solutions used for bacteria and cells need sterilization by a HG-50 Autoclave. The white light source for photodynamic treatment was supplied by a L-150A cold light as a simulated sunlight with a range of $200 \mathrm{~nm}$ to $1200 \mathrm{~nm}$. The wavelength with the strongest energy density is around $450 \mathrm{~nm}$.

The recombinant Escherichia coli (E. coli) antitoxin RelB (RelB), recombinant E. coli relaxosome protein TraY (TraY), recombinant $E$. coli uncharacterized protein yjbL (yjbL) were purchased from MyBiosource, USA. All the proteins were stored in 10 $\mathrm{mM}$ Tris-HCl buffer ( $\mathrm{pH} 8.0$ ), containing $1 \mathrm{mM}$ EDTA and 10\% glycerol to keep biology activity. Before use, the proteins need hyperfiltration to remove the salt and glycerol.

The bacteria were detected by an AutoFlex II MALDI-TOF MS (Bruker-Daltonics). DHB matrix and SA matrix were respectively applied for the bacteria samples and protein samples, which were prepared with a concentration of $20 \mathrm{mg} / \mathrm{mL}$ in a solution containing $50 \%(\mathrm{v} / \mathrm{v}) \mathrm{H}_{2} \mathrm{O}, 49.9 \%(\mathrm{v} / \mathrm{v}) \mathrm{ACN}$ and $0.1 \%(\mathrm{v} / \mathrm{v})$ TFA. All the samples mixed with the matrix (1:1) were dropped on a MALDI polished plate to generate the dried spots. Mass spectra for bacteria and cancer cells range from 3000 to $10000 \mathrm{~m} / \mathrm{z}$ were acquired by the reflection mode at a laser frequency of $25.0 \mathrm{~Hz}$. All the MS results were accumulated through more than 1000 laser shots to ensure the signal to noise $(\mathrm{S} / \mathrm{N})$ ratios were higher than 10 .

Bacteria and cancer cell culture. E. coli (strain ATCC25922), Bacillus subtilis (B. sub, strain ATCC33677), Vancomycinresistant Enterococcus faecalis (VRE, strain ATCC51299), and Methicillin-resistant Staphylococcus aureus (MRSA, strain ATCC43300) were provided by American Type Culture Collection. All the bacteria species were picked up from the colonies of the LB agar plate and cultured with the LB broth medium.

The LB agar plate was made of LB agar powder which was purchased from Invitrogen. The LB agar powder $(32 \mathrm{~g})$ was dissolved into $1 \mathrm{~L}$ of ultrapure water, then the solution was sterilized by autoclave in high temperature. Keeping the solution above $50^{\circ} \mathrm{C}$ from solidification, hot liquid LB agar solution was dumped into a petri dish, then cooled down to get the solid LB agar plate. In the whole period, the solid LB agar plate should be stored in a sterile atmosphere to keep away from pollution. The LB broth medium was prepared by LB broth base (Invitrogen). Similarly, the LB broth base (20 g) was dissolved in $1 \mathrm{~L}$ of ultrapure water. After sterilized by autoclave, the LB solution was transferred and stored in a sterile atmosphere.

For the proliferation of bacteria, the bacteria seeds were picked up from a colony of solid LB agar plate and suspended into $5 \mathrm{~mL}$ of LB broth medium. The suspension was then incubated at $37^{\circ} \mathrm{C}$ with vibration overnight in a Shaker MaxQ 4000 \& Heidolph Incubator Shaker (Thermo Scientific). After that, the turbid bacteria suspension was centrifuged at about $2000 \times \mathrm{g}$ for $5 \mathrm{~min}$ to remove LB medium and washed with pure water twice. The fresh bacteria were re-dispersed into pure water and diluted to a concentration of $\sim 1 \times 10^{8}$ colony-forming unit $(\mathrm{cfu}) / \mathrm{mL}$ calculated by $\mathrm{OD}_{600}$ value.

HL-60 cells were supplied by American Type Culture Collection (ATCC) and chosen as a cancer cell model for photodynamic treatment. The cells were cultured in a HERAcell $150 \mathrm{i} \mathrm{CO}_{2}$ incubator $\left(5 \% \mathrm{CO}_{2}, 37^{\circ} \mathrm{C}\right)$ with RPMI 1640 medium, containing $20 \%$ of 
FBS, $100 \mu \mathrm{g} / \mathrm{mL}$ of streptomycin and $100 \mu \mathrm{g} / \mathrm{mL}$ penicillin. After proliferation, the cells were centrifuged, washed with $1 \times$ PBS buffer solution, and re-dispersed into fresh RPMI 1640 medium. The cells were diluted and counted to $\sim 3 \times 10^{5}$ cells $/ \mathrm{mL}$.

Photodynamic oxidation of proteins. The oxidation of pure proteins was detected with MALDI-TOF MS. Firstly, after removing the salt and glycerol, $100 \mu \mathrm{L}$ of protein solution with a concentration of $100 \mu \mathrm{g} / \mathrm{mL}$ was transferred into the 96-well plate, adding MB into the solution to ensure the final concentration to $20 \mu \mathrm{M}$. After illumination by white light with a power of $60 \mathrm{~mW} / \mathrm{cm}^{2}$ for different time, $1 \mu \mathrm{L}$ of protein solution was deposited on the MALDI plate mixed with $1 \mu \mathrm{L}$ of SA matrix. After dried, the protein sample was detected with the MALDI-TOF MS.

Cytotoxicity experiment with CCK-8 kit. As a comparison, cytotoxicity experiment with CCK-8 kit was determined to evaluate the mortality rate of $H L-60$ cells. After photodynamic treatment, $10 \mu \mathrm{L}$ of CCK-8 solution from the kit was added into the cellular solution in the 96-well plate and the cells were incubated at $37^{\circ} \mathrm{C}$ in $5 \% \mathrm{CO}_{2}$ atmosphere for $4 \mathrm{~h}$ in a dark environment. Then the absorbance values of the cellular solution under $450 \mathrm{~nm}$ of light were analyzed with the enzyme-labeled instrument. The mortality rates were then calculated by the ratio of reduced absorbance value to the absorbance value of cells without photodynamic treatment.

Photodynamic treatment for mixture samples. For the bacteria mixture sample, $100 \mu \mathrm{L}$ of $E$. coli and $100 \mu \mathrm{L}$ of $M R S A$ both with a concentration of $\sim 5 \times 10^{7} \mathrm{cfu} / \mathrm{mL}$ were mixed and incubated with $20 \mu \mathrm{M}$ of $\mathrm{MB}$ for $2 \mathrm{~h}$. Then the bacteria mixture was centrifuged to remove excess MB, washed and re-dispersed into pure water. $1 \mu \mathrm{L}$ of the mixture was dropped on the MALDI plate. After white light irradiation for 9 min, the bacteria mixture was mixed with $1 \mu \mathrm{L}$ of DHB matrix and dried in room temperature. The dried sample was in-situ analyzed with MALDI-TOF MS and the oxidation rates of specific oxidized proteins from E. coli and MRSA were respectively calculated. Similarly, the mixture of MB-treated E. coli and pure MRSA, and the mixture of pure E. coli and MBtreated MRSA were tested. For mixture sample of cancer cells and bacteria, $100 \mu \mathrm{L}$ of $H L-60$ cells with a concentration of $\sim 3 \times 10^{5}$ cells $/ \mathrm{mL}$ was mixed with $100 \mu \mathrm{L}$ of $E$. coli with a concentration of $\sim 5 \times 10^{7} \mathrm{cfu} / \mathrm{mL}$ in the RPMI 1640 medium. The mixture was incubated with $20 \mu \mathrm{M}$ of MB for $4 \mathrm{~h}$, then centrifuged to remove residual MB, and re-dispersed into culture medium. The mixture was then transferred into the 96-well plate for $9 \mathrm{~min}$ of light irradiation. After that, the mixture was centrifuged to remove culture medium, washed with $1 \times$ PBS buffer twice and re-dispersed into pure water. $1 \mu \mathrm{L}$ of the mixture was deposited on the MALDI plate, mixed with $1 \mu \mathrm{L}$ of DHB matrix, and in-situ detected by MALDI-TOF MS to get the oxidation rates. The mixture of MB-treated $E$. coli and pure $H L-60$, and the mixture of pure E. coli and MB-treated $H L-60$ were tested.

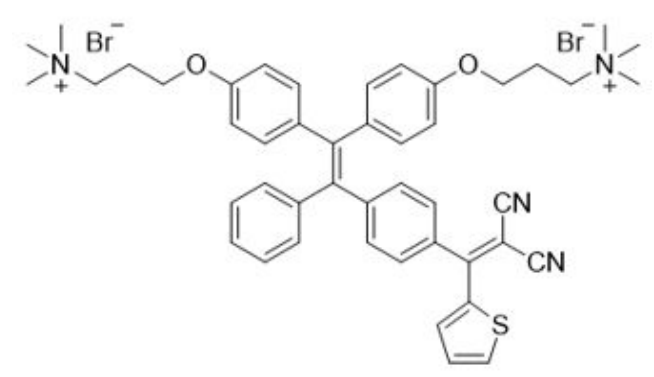

Figure SI-1. The structure of TPETH. 


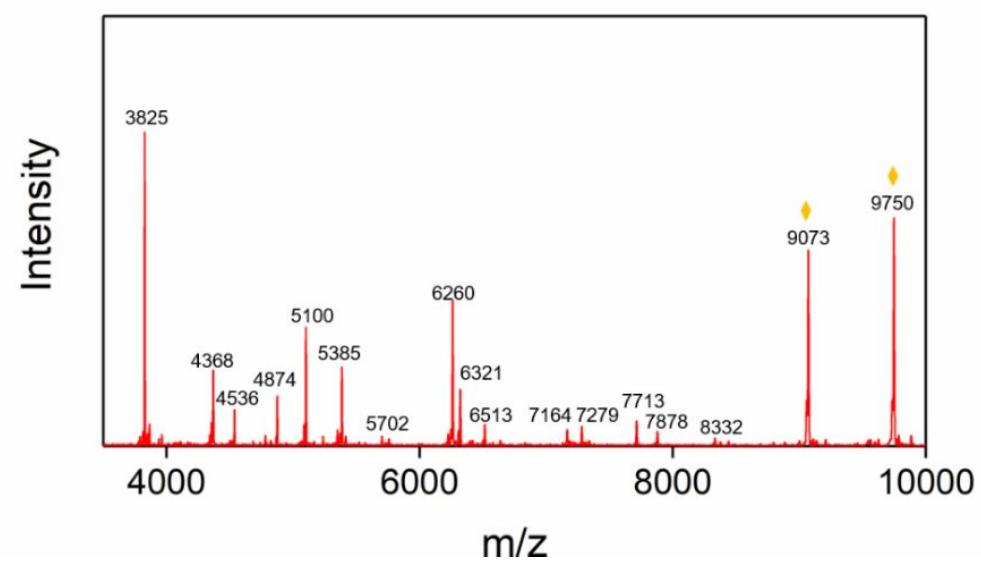

Figure SI-2. Fingerprint of E. coli by MALDI-TOF MS. The concentration of bacteria is $1.0 \times 10^{8} \mathrm{cfu} / \mathrm{mL}$.

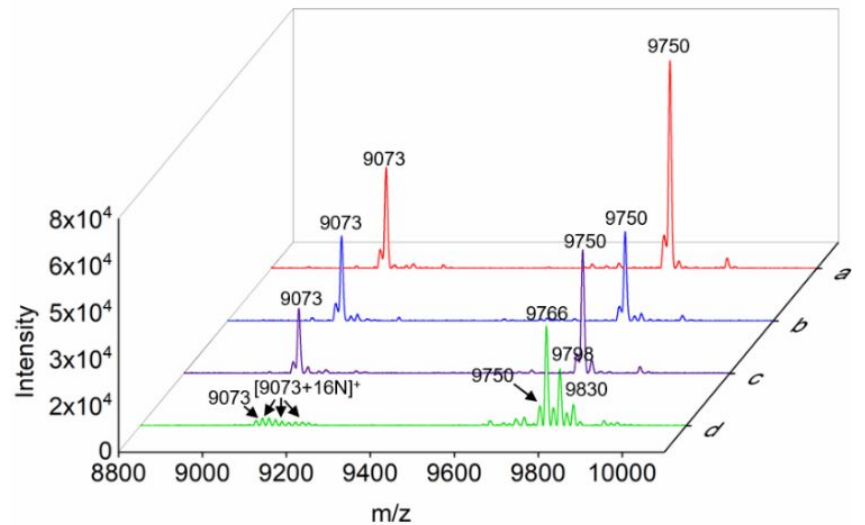

Figure SI-3. Oxidized mass peaks of (a) E. coli, (b) E. coli under light illumination, (c) E. coli with MB, (d) E. coli with MB under light illumination.
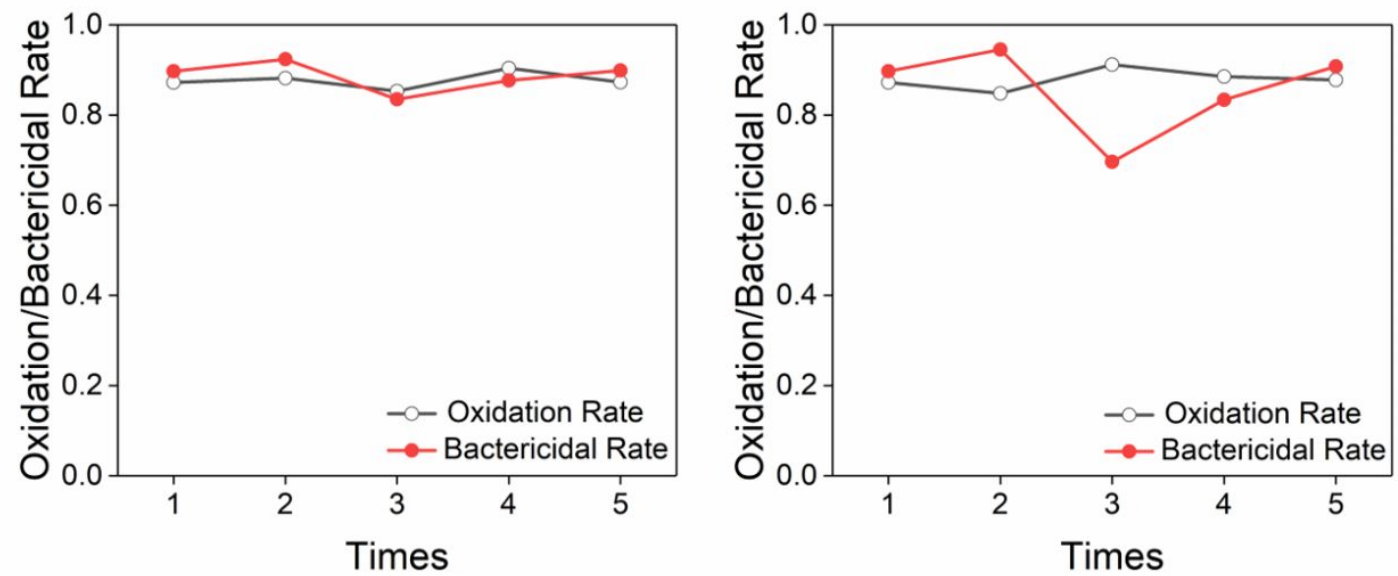

Figure SI-4. The accuracy and repeatability of oxidation rate and bactericidal rate. (A) The oxidation rates and bactericidal rates in an experiment with 5 parallel samples; (B) The oxidation rates and bactericidal rates in 5 times of experiments. The $E$. coli were treated with $20 \mu \mathrm{M}$ of $\mathrm{MB}$ and 9 min of illumination time. 

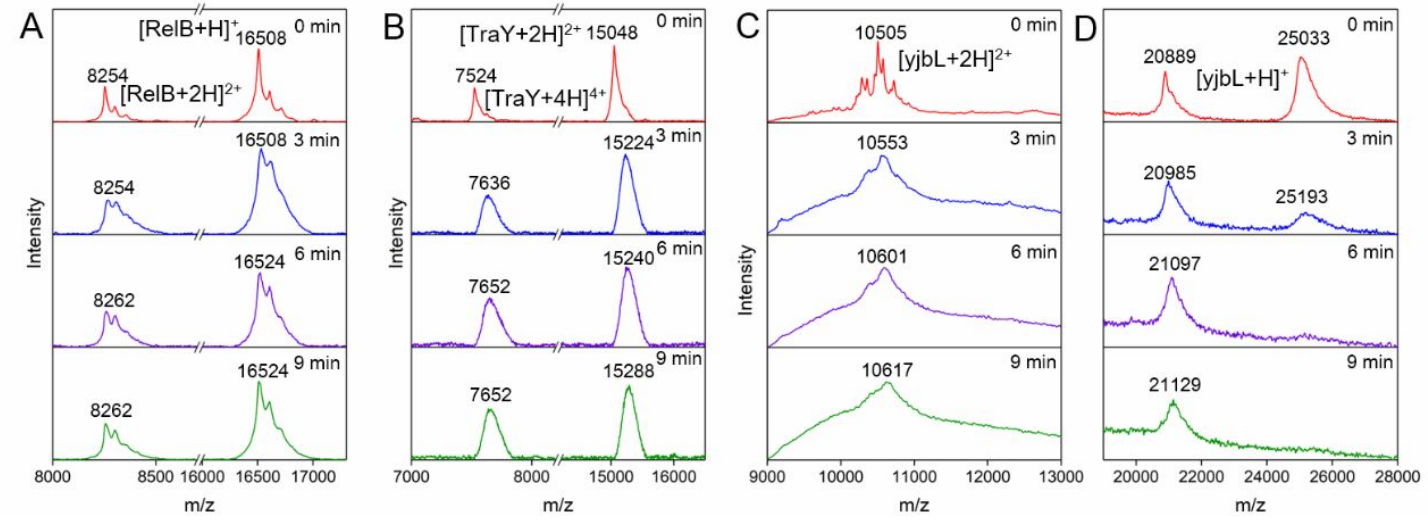

Figure SI-5. MALDI-TOF MS of pure proteins after photodynamic treatment for different illumination time. (A) RelB protein, (B) TraY protein, and (C and D) yjbL protein. All the proteins were recombinant with specific target sequences, so the mass weight is larger than the original ones. The protein concentrations are $100 \mu \mathrm{g} / \mathrm{mL}$ respectively, and the power of white light is $\sim 60 \mathrm{~mW} / \mathrm{cm}^{2}$.

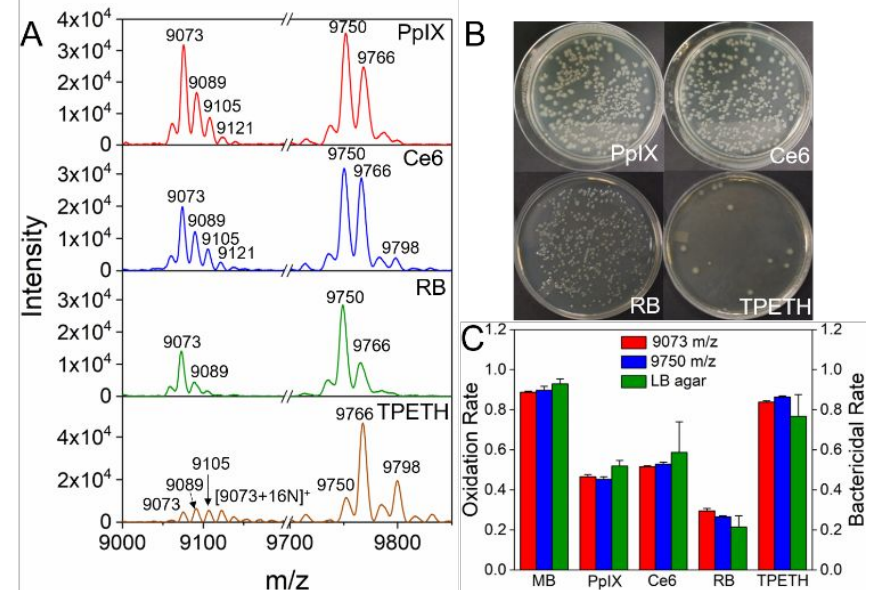

Figure SI-6. Photodynamic treatment for E. coli with different photosensitizers. (A) In-situ protein oxidation detection of $E$. coli incubated with different photosensitizers by MALDI-TOF MS; (B) Bacteria proliferation of $E$. coli after photodynamic treatment with different photosensitizers by LB agar colony; (C) Comparison between the oxidation rates and the bactericidal rate for photodynamic treatment of $E$. coli with different photosensitizers. The concentration of bacteria was $1.0 \times 10^{8} \mathrm{cfu} / \mathrm{mL}$, the power of white light was $\sim 30 \mathrm{~J} / \mathrm{cm}^{2}$.

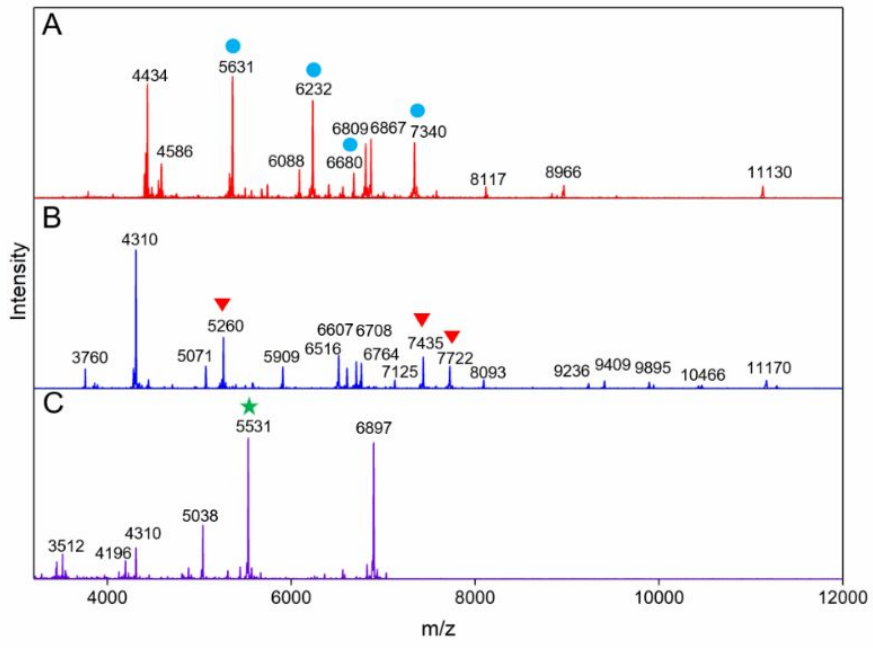

Figure SI-7. MS fingerprints of (A) $V R E$, (B) B. Sub, and (C) MRSA. The concentrations of bacteria are all $1.0 \times 10^{8} \mathrm{cfu} / \mathrm{mL}$. The marked mass peaks refer to the proteins oxidized by ROS. 
Table SI-1. The oxidized mass peaks detected with MALDI-TOF MS in different bacteria species after photodynamic treatment.

\begin{tabular}{|c|c|c|}
\hline Bacteria & Original peak $( \pm \mathbf{3} \mathbf{~ m} / \mathbf{z})$ & Oxidation Peaks $( \pm \mathbf{3} \mathbf{~ m} / \mathbf{z})$ \\
\hline \multirow{2}{*}{ E. coli } & 9073 & $9089,9105,9121,9137,9153,9169,9185,9201,9217, \ldots$ \\
\cline { 2 - 3 } & 9750 & $9766,9798,9830$ \\
\hline \multirow{2}{*}{ VRE } & 5361 & 5377,5393 \\
\cline { 2 - 4 } & 6232 & $6248,6264,6280$ \\
\cline { 2 - 4 } & 6680 & $6696,6712,6728,6744,6760$ \\
\cline { 2 - 4 } & 7340 & $7356,7372,7388,7404,7420$ \\
\hline \multirow{2}{*}{ B. Sub } & 5260 & 5276,5292 \\
\cline { 2 - 4 } & 7435 & 7451,7467 \\
\cline { 2 - 4 } & 7722 & 7738,7754 \\
\hline \multirow{2}{*}{ MRSA } & 5531 & 5547 \\
\hline
\end{tabular}

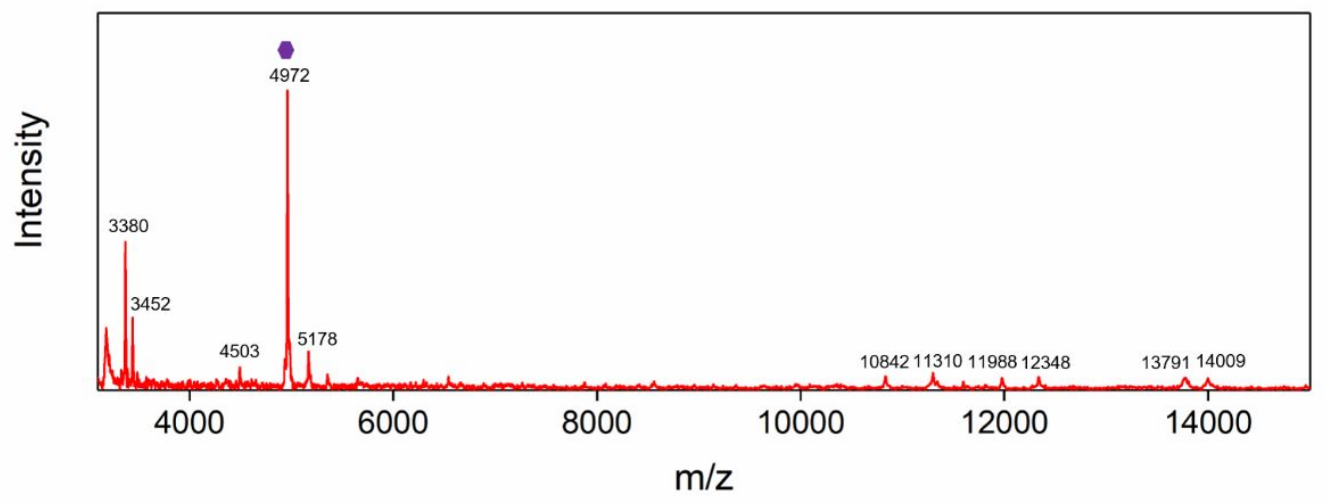

Figure SI-8. MS fingerprint of $H L-60$ cancer cells. The concentration is $3.0 \times 10^{5}$ cells $/ \mathrm{mL}$. 


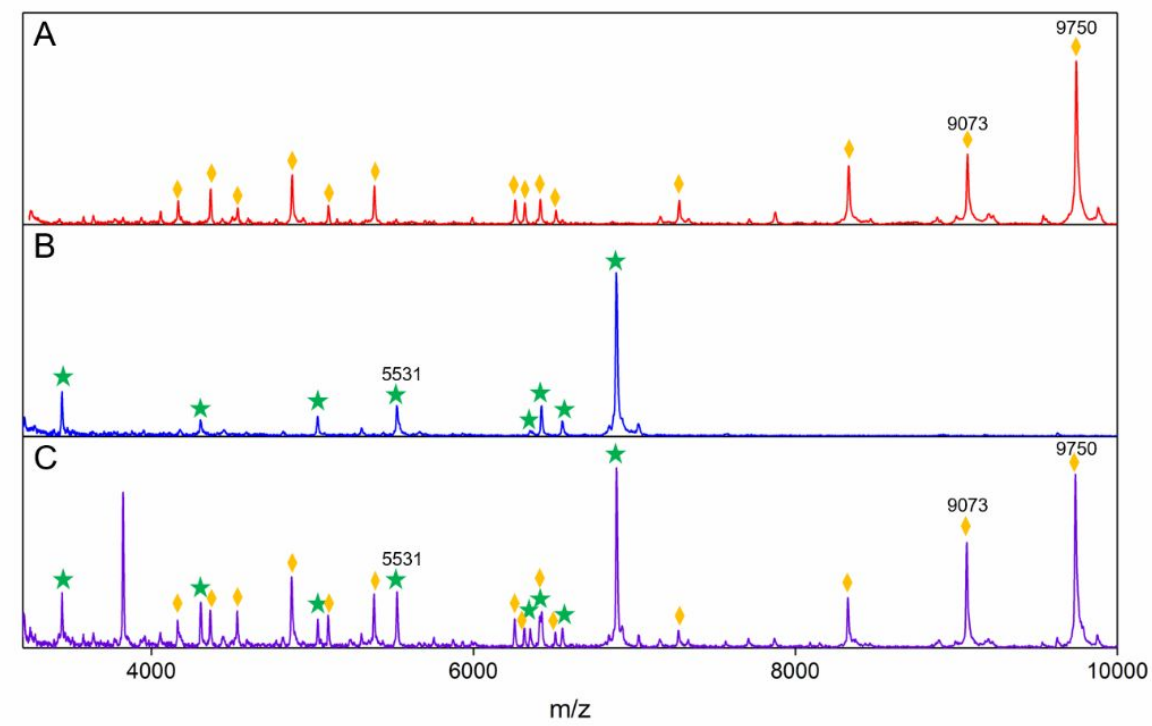

Figure SI-9. MALDI-TOF MS fingerprints of (A) E. coli, (B) MRSA, and (C) mixture of E. coli and MRSA. The concentrations of bacteria are both $5.0 \times 10^{7} \mathrm{cfu} / \mathrm{mL}$. 